\title{
Misperceptions of peer gambling norms among adolescents: Analysis of a national sample in Finland
}

\author{
Susanna Raisamo ${ }^{1^{*}}$, Tomi Lintonen ${ }^{2}$ \\ ${ }^{1}$ School of Health Sciences, University of Tampere, Tampere, Finland; *Corresponding Author: susanna.raisamo@uta.fi \\ ${ }^{2}$ The Finnish Foundation for Alcohol Studies, Helsinki, Finland
}

Received 11 January 2012; revised 28 February 2012; accepted 16 March 2012

\begin{abstract}
Introduction: Misperceptions of peer drinking norms are widely documented in the US student populations and are associated with increased personal consumption. Few studies have examined misperceptions of peer gambling, and none of these have been conducted among adolescents in the European context. In a national sample, we examined misperceptions of peer gambling in Finland. Tenets of the social norms approach form a framework for discussion of the findings. Methods: Participants were 4526 adolescents aged 12 to 18 years who completed the nationwide Adolescent Health and Lifestyle Survey in 2011. Main measures were gambling behavior and the perception of same age-sex peers' gambling. Misperception was an overestimation of the frequency of gambling by others compared to the actual frequency of gambling. Results: Adolescents held substantial misperceptions of peer gambling, imagining they gambled much more than they actually did. Age, sex, and gambling behavior were correlated with the perceptions. The extent of misperception was greatest among monthly gamblers, whereas nongamblers and daily gamblers were more accurate in their perceptions. Estimations of peers' gambling frequency were more accurate in boys than in girls and among those aged 12 years than among older adolescents. Conclusion: Our findings suggest that adolescent gambling prevention efforts could benefit from adopting a social norms approach; that is, correcting gambling-related misperceptions might discourage gambling and protect adolescents from adopting more severe gambling patterns.
\end{abstract}

Keywords: Adolescent; Gambling; Social Norms; Misperceptions; Peers

\section{INTRODUCTION}

In theories of health behavior, social norms have an important explanatory role in determining individuals' behavior and beliefs [1-3]. Beliefs concerning consequences of behavior and the opinions of others have a powerful effect on an individual's behavior [1,4]. According to Social Norms Theory, our intention to act, behavior, and beliefs are influenced by perceptions (whether or not accurate) of how other people behave; if individuals perceive a certain behavior among their peers to be common and feel it is important to conform to social norms they are more likely to engage in that behavior themselves than would otherwise be the case $[4,5]$.

Briefly, two different types of social norms are incorporated into the social norms approach, descriptive and injunctive norms. Descriptive norms, also referred to as perceived prevalence, are beliefs about in the actions of the majority of one's social group. Injunctive norms refer to an individual's beliefs about what their peers find socially acceptable. Both beliefs concerning behavioral consequences and the opinions of others have a powerful effect on an individual's behavior [4]. Consistent with this approach, misperceptions of norms are discrepancies between the actual norm (the prevalence of behavior) and the perceived norm (the perceived prevalence of behavior). Misperceptions are of particular concern if individuals base their actions on these misperceptions [4].

Normative misperceptions have been extensively investigated in the US among college and university student populations [6]. A considerable amount of research indicates that individuals tend to overestimate how heavily and frequently their peers drink alcohol, and that these misperceptions lead to increased personal consumption [4]. In the US and within the alcohol misuse field, interventions based on a social norms approach have become the most widely used prevention approach, and such interventions are effective in reducing alcohol misuse [7]. 
Other studies have demonstrated normative misperceptions of other drug use, smoking, body weight, and sexual behavior [8-10]. Research evidence about the misperceptions of norms of adolescent gambling, however, is fairly scarce and most studies have been conducted outside the European context [11-13]. Larimer and Neighbors [12] reported two studies examining normative misperceptions and the impact of descriptive and injunctive norms on college student gambling. They discovered that both perceived descriptive and injunctive norms uniquely predicted self-reported gambling among undergraduate students, mean age 19 years. Given the paucity of research, the potential usefulness of the social norms approach as a prevention strategy to reduce under-aged gambling and to minimize gambling-related negative consequences and misperceptions has remained largely unexplored.

Adolescence is a phase of life usually characterized by participation in risk behaviors like alcohol drinking and tobacco smoking. The risk of these behaviors is that they make adolescents more susceptible to developing addictions. In the sphere of youth addictions, youth gambling is often referred to as a non-substance-related behavioral addiction [14-16] that has received increasing attention in several countries as a significant public health concern $[17,18]$. Gambling is a potentially addictive activity because it is socially reinforcing and encouraged by peers, factors that contribute to the maintenance of risk behaviors [12].

Gambling research among young people between 9 to 21 years of age is limited and mainly prevalence-focused [18]. The popularity of gambling among youth is high. In Finland, approximately over $70 \%$ of $9^{\text {th }}$ grade boys (aged 15 and 16 years) and 25\% of girls aged 15 and 16 years play on slot machines at least once a month [19]. Finland has a national gambling monopoly regulated by the Finnish gambling law. The minimum legal age for gambling has been 15 years since 1976. An age limit of 18 years was set in October 2010, but slot machine owners were allowed a transition time to change the age limit until July 2011, meaning that during data collection for the present study, the age limit for using slot machines was 15 years and for all other gambling forms, 18 years.

Due to legal and cultural differences related to gambling between countries, social norms are likely to vary. Using a nationally representative sample of 12 to 18 year-old adolescents in Finland, our aims for the present study were, to examine the extent of misperceptions of peer gambling and then to examine the extent to which these perceptions related to an individual's gambling behavior. Finally, particular attention was paid to the core tenets of the social norms approach, which forms a framework for the discussion of our findings.

\section{MATERIAL AND METHODS}

We used data from the 2011 Adolescent Health and Lifestyle Survey, a nationwide mailed survey conducted every other year in Finland since 1977 among 12-, 14-, 16-, and 18-year-olds. The mean ages of respondents were 12.6, 14.6, 16.6, and 18.6 years. The sample was drawn from the Population Register Centre on the basis of particular dates of birth, so that all Finns born on the sample days were included. Three re-inquiries were mailed to nonrespondents. Approval for the study was obtained from the Ethics Committee of the Pirkanmaa Hospital District, Tampere, Finland. More detailed information on the survey methodology can be found in Rimpelä et al. [20].

The total number of respondents was 4566 (1899 boys, 2667 girls). The overall response rate was $46 \%$. The number of respondents and response rates among boys by age was: $320(47 \%)$ of 12-year-old, 621 (45\%) of 14year-old, 566 (37\%) of 16-year-old, and 392 (26\%) of 18-year-old. For girls, the corresponding rates were: 326 (55\%) of 12-year-old, 777 (60\%) of 14-year-olds, 868 (58\%) of 16-year-old, and 696 (52\%) of 18-year-olds.

\subsection{Measures}

Gambling behavior was measured by the following item: "During the past 6 months, have you gambled for money?" with response alternatives "no", "yes, daily or almost daily", "a couple of times a week", "a couple of times a month", and "less often". After excluding cases with missing information $(n=40)$, the number of valid responses was 4526 . To facilitate further analysis, gambling behavior was used to categorize respondents as into non-gamblers, occasional gamblers, and frequent gamblers. Due to the small number of daily gamblers, daily and weekly gamblers were combined into frequent gamblers. Those gambling "a couple of times a month" and "less often" were combined into occasional gamblers. Non-gamblers had not gambled over the 6-month period preceding the survey.

Perception of peer gambling was derived from a threecategory question: "If you compare yourself with other same age-sex peers, do you think that most of them gamble "more than you", "as much", "less than you”? The frequency of missing values for this variable was $1.6 \%$ $(n=32)$. Misperception was defined as an overestimation of the frequency of gambling by others when compared with the actual rate. For example, the extent of misperception among boys who engaged in gambling "a couple of times a month" was calculated by subtracting weekly and daily gambling prevalence rates (see Table 1: 18.6\% $+4.1 \%=22.7 \%$ ) from the proportion of respondents perceiving others as gambling more within the category "a couple of times a month" (Table 2: 75.8\%). The misperception rate was $75.8 \%-22.7 \%=53.1 \%$. 
Table 1. Adolescent gambling, by age and sex (\%).

\begin{tabular}{cccccc}
\hline $\begin{array}{c}\text { Total } \\
\mathrm{N}=4526\end{array}$ & \multicolumn{5}{c}{ Self-reported gambling (\%) } \\
\hline Age, sex & Daily & Weekly & Monthly & Less often & Non-gambler \\
\hline Boys & & & & & \\
12 & 0.6 & 3.8 & 5.7 & 15.6 & 74.3 \\
14 & 2.6 & 16.3 & 14.5 & 22.1 & 44.5 \\
16 & 6.6 & 28.0 & 25.0 & 16.8 & 23.6 \\
18 & 6.4 & 26.3 & 22.4 & 20.6 & 24.2 \\
$12-18$ & 4.1 & 18.6 & 16.9 & 18.8 & 41.7 \\
Girls & & & & & \\
12 & - & 0.3 & 3.2 & 9.5 & 87.0 \\
14 & 0.6 & 1.6 & 5.2 & 17.5 & 75.1 \\
16 & 0.7 & 3.1 & 11.3 & 26.6 & 58.2 \\
18 & 0.9 & 4.3 & 9.4 & 23.5 & 62.0 \\
$12-18$ & 0.6 & 2.3 & 7.3 & 19.3 & 70.6 \\
\hline
\end{tabular}

\subsection{Data Analyses}

Data analyses were performed using SPSS statistical software, version 18.0 for Windows software. We performed cross-tabulation analyses and the independence of the variables was tested using Pearson's $\chi^{2}$ test (twotailed). A $p$ value of less than 0.05 was considered statistically significant. Because there were significant sex differences related to gambling behavior, the results are presented separately for boys and girls.

\section{RESULTS}

Of 4526 respondents, $44 \%$ had gambled during the past 6 months and 56\% were non-gamblers. Of the respondents, $2 \%$ reported gambling daily, $10 \%$ were weekly gamblers, $12 \%$ were monthly gamblers, and $20 \%$ reported having gambled less often. Boys gambled more than girls and gambling increased with age (Table 1).

Table 2 shows that normative perceptions of peers' gambling correlated with the respondent's age, sex, and gambling behavior. The majority of adolescents perceived their same age-sex peers as gambling more than themselves; among both boys and girls, over $70 \%$ shared this view (Table 2).

Figure 1 shows the perceived gambling of others divided into two components: the percentage of those actually gambling more and the percentage misperceived as gambling more. This division is shown for each gambling behavior category from non-gambling to daily gambling. Boys were less likely to misperceive peers' gambling than girls. In both sexes, the proportion of misper- ception was greatest in the gambling category of "a couple of times a month". Non-gamblers and daily gamblers held more accurate perceptions when compared to other groups (Figure 1).

\section{DISCUSSION}

Our findings indicate that adolescents held substantial misperceptions of peer gambling. Both boys and girls overestimated the frequency of the gambling of their same age-sex peers, imagining that they gambled much more than they actually did. Age, sex, and gambling behavior were correlated with the perceptions. The extent of misperception was greatest among monthly gamblers, whereas non-gamblers and daily gamblers held more accurate perceptions. Estimations of peer gambling frequency were more accurate in boys than girls and among those aged 12 than among older adolescents.

The possibilities for comparisons with previous studies are largely limited, as research examining misperceptions of peer gambling is scarce and existing studies were conducted outside the European context. As previously reported [12], however, our findings indicated that there are misperceptions at any gambling frequency level, from non-gambling to daily gambling. This finding is highly relevant from the perspective of social norms theory, as there is evidence that misperceptions determine an individual's behavior [4]. Based on our results, the extent of misperceptions was greatest among monthly
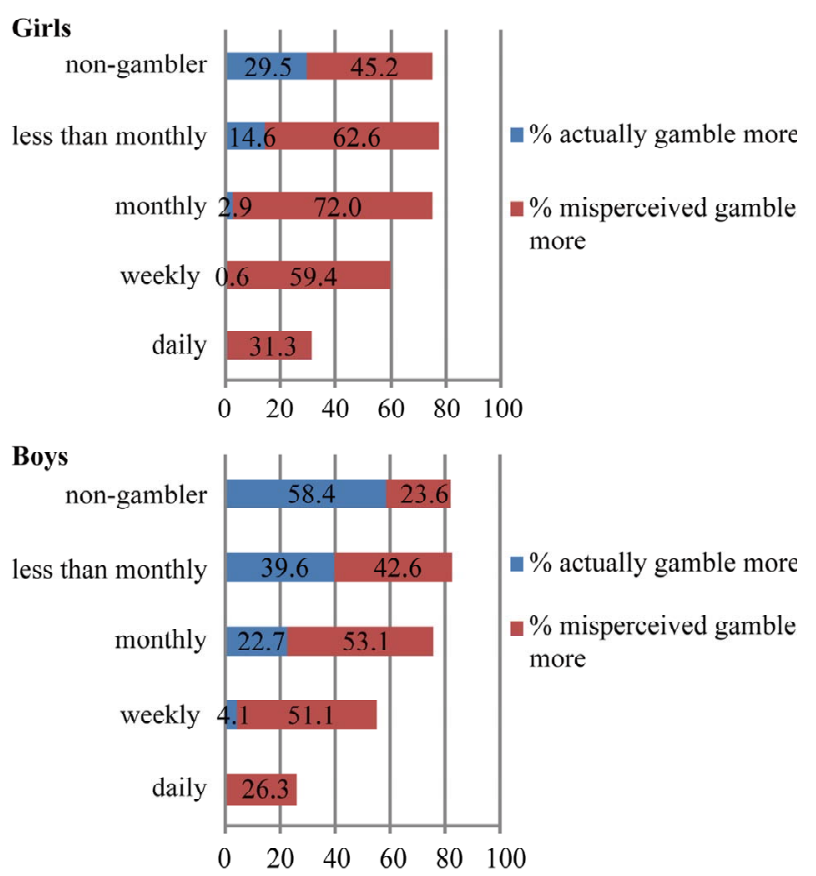

Figure 1. Percentage of those perceiving others as gambling more than themselves divided into two components: the percentage actually gambling more and the percentage misperceived as gambling more. 
Table 2. Distribution (\%) of perceptions of peers' gambling by age, sex, and gambling behavior.

\begin{tabular}{|c|c|c|c|c|c|c|}
\hline \multirow[b]{2}{*}{ Age, sex, gambling behavior } & \multirow[b]{2}{*}{$\mathrm{N}$} & \multicolumn{3}{|c|}{ Perception of peers' gambling } & \multirow[b]{2}{*}{ Total (\%) } & \multirow[b]{2}{*}{ p-value } \\
\hline & & $\begin{array}{c}\text { Peers gamble } \\
\text { more (\%) }\end{array}$ & $\begin{array}{c}\text { Peers gamble as } \\
\text { much (\%) }\end{array}$ & $\begin{array}{c}\text { Peers gamble less } \\
(\%)\end{array}$ & & \\
\hline Gender $(n=4070)$ & & & & & & 0.002 \\
\hline Boys & $(1758)$ & 72.6 & 22.9 & 4.4 & 100 & \\
\hline Girls & $(2312)$ & 74.7 & 22.8 & 2.5 & 100 & \\
\hline Age $(n=4070)$ & & & & & & 0.000 \\
\hline 12 & (499) & 49.7 & 44.5 & 5.8 & 100 & \\
\hline 14 & $(1255)$ & 80.1 & 17.1 & 2.8 & 100 & \\
\hline 16 & $(1334)$ & 78.4 & 19.1 & 2.5 & 100 & \\
\hline 18 & (982) & 71.8 & 24.3 & 3.9 & 100 & \\
\hline \multicolumn{7}{|l|}{ Gambling behavior } \\
\hline Girls $(n=2296)$ & & & & & & 0.000 \\
\hline daily & (16) & 31.3 & 31.3 & 37.5 & 100 & \\
\hline weekly & (70) & 60.0 & 31.4 & 8.6 & 100 & \\
\hline monthly & (211) & 74.9 & 21.3 & 3.8 & 100 & \\
\hline less than monthly & $(545)$ & 77.2 & 21.3 & 1.5 & 100 & \\
\hline non-gambler & (1454) & 74.7 & 23.3 & 2.0 & 100 & \\
\hline Boys $(n=1747)$ & & & & & & 0.000 \\
\hline daily & (80) & 26.3 & 43.8 & 30.0 & 100 & \\
\hline weekly & (366) & 55.2 & 38.5 & 6.3 & 100 & \\
\hline monthly & (331) & 75.8 & 21.8 & 2.4 & 100 & \\
\hline less than monthly & (354) & 82.2 & 16.4 & 1.4 & 100 & \\
\hline non-gambler & (616) & 82.0 & 15.1 & 2.9 & 100 & \\
\hline
\end{tabular}

gamblers. Monthly gambling might not be a problem as such, but when combined with biased beliefs about peer gambling it could be a signal of vulnerability to adopt even more severe gambling patterns and thus, constitutes a risk for developing a gambling problem.

Notably, peer gambling frequency estimates were more accurate in boys than in girls. This finding was not surprising. Girls in general gamble much less than boys and there is some evidence from previous social norms studies for similar sex effects on misperceptions [21,22]. By age, the percentage of adolescents who perceived that "others gamble much more" was fairly similar across 14 , 16 , and 18 year olds, whereas the rate of this perception was considerably lower among adolescents aged 12 years. This is likely due to the fact that participation in gambling activities among 12-year-old adolescents in Finland is rare.

Overall, the reasons for misperceptions remain uncertain and further studies are required. To develop more targeted and comprehensive prevention efforts, a better understanding of the misperceptions and their origination is important. Complex interplay between the individual and socio-environmental factors is likely. As the magnitude of misperceptions may reflect changes in gambling laws and other country-specific factors, misperceptions should be monitored over time to determine the persistence of misperceptions.

Our findings have implications for gambling prevention programs in Finland and elsewhere. The basis of gambling prevention among adolescents has mainly been undertaken through legislative regulations. For the prevention of under-age gambling, a minimum age law is a key component, but even in the case of strict legislation, its successful enforcement can be difficult. Our findings suggest that despite the current minimum-age legislation for gambling in Finland (18 years), a large percentage of minors engaged in gambling during the previous 6 months. As such, legislation in itself is not likely to 
change the social norm in the short run, but when combined with other efforts, we could assume that, in the long run and as a consequence of legislative restrictions and greater public awareness of the negative consequences of gambling, the number of under-aged gamblers will also be reduced.

As family and school are central components of the youth socialization process, prevention activities may easily be promoted through these environments. Parents have an influential role in the lives of adolescents and can be role models for gambling and carriers of misperceptions [6]. Therefore, we should not underestimate their importance. It is necessary to adopt a more active role regarding parental involvement and familial issues when planning intensive health education campaigns. In countries where health education is introduced as an independent school subject, teachers have a great potential to incorporate gambling-related issues as part of the curriculum, through which preventive messages could be easily delivered throughout the different grade levels. So far, in our national health education curriculum, adolescent gambling issues have not received attention. Obviously, more effort in general will also be needed to increase teacher understanding and awareness of adolescent gambling as a serious concern.

We currently lack a simple and effective gambling prevention strategy targeting the youth population. The findings of our study could be used as a starting point for planning health education regarding gambling and particularly, to examine the applicability of the social norms approach. Rather than focusing on the risks and negative consequences of gambling, the social norms approach can offer us an alternative to conventional approaches of health education [8]. Although this approach has mostly been studied in the alcohol field among college and university students in the US, the principles of this approach are highly applicable to a range of health behaviors [6].

Correcting normative misperceptions by providing youth with accurate and credible information about peer gambling behavior and attitudes may protect adolescents from adopting more severe patterns of gambling. We found considerable misperceptions of peer gambling among adolescents, regardless of their individual gambling status, suggesting that all adolescents are likely to benefit from correcting normative misperceptions. It should be noted, however, that the current policy, and individual and community level strategies already available to reduce gambling in society continue to be important. Among these are support-based efforts, such as therapies, telephone helplines, and various self-help programs. At the same time, we conclude that if normative misperceptions are not targeted for correction, a potentially very powerful component of prevention is neglected. We encourage researchers and professionals in the field to learn more about the social norms approach and to consider it as an alternative prevention strategy to conventional approaches.

This study has limitations related to the use of selfreport measures in a cross-sectional study design. Causal relationships cannot be inferred from the data and we cannot exclude the possibility of over- or under-reporting. On the other hand, the use of self-reports cannot be avoided in a study of this nature. Our study focused on descriptive gambling norms. Due to the limited space in the questionnaire and the nature of the questionnaire (monitoring health and health behaviors), we were unable to use the Perceived Norms Subscale [23], which is designed to measure widely perceived descriptive gambling norms. Further, we did not have data on injunctive norms to evaluate the extent to which adolescents believe that their peers approve or disapprove of gambling. Finally, caution must be taken in generalizing results to other cultural contexts because there are considerable variations in gambling policies among different countries (i.e., legal restrictions) and in cultural values. Moreover, the low response rate among 18-year-olds requires caution in generalizing the results of this age group. Despite these limitations, our study has notable strengths. The use of a nationwide database allowed us to extend previous research. This study is the first of its kind in Finland and yielded several useful findings that can be applied to gambling prevention programs.

\section{ACKNOWLEDGEMENTS}

This study was supported by the Finnish Foundation for Alcohol Studies, Helsinki, Finland and the Ministry of Social Affairs and Health, Helsinki, Finland.

\section{REFERENCES}

[1] Ajzen, I. (1991) The theory of planned behaviour. Organizational Behaviour and Human Decision Processes, 20, 179-211.

[2] Godin, G. and Kok, G.J. (1996) The theory of planned behavior: A review of its applications to health-related behaviors. American Journal of Health Promotion, 11, 87-98. doi:10.4278/0890-1171-11.2.87

[3] Bandura, A. (2001) Social cognitive theory: An agentic perspective. Annual Review Psychology, 52, 1-26. doi:10.1146/annurev.psych.52.1.1

[4] Berkowitz, A.D. (2003) The social norms approach: Theory, research and annotated bibliography. http://alanberkowitz.com/articles/social_norms.pdf

[5] Lapinski, M.K. and Rimal, R.N. (2005) An explication of social norms. Communication Theory, 15, 127-134. doi:10.1111/j.1468-2885.2005.tb00329.x

[6] Perkins, H.W. (2002) Social Norms and the prevention of alcohol misuses in collegiate contexts. Journal of Studies on Alcohol, 14, 164-172. 
[7] Moreira, M., Smith, L. and Foxcroft, D. (2010) Social norms interventions to reduce alcohol misuse in university or college students. The Cochrane Collaboration, 3. doi:10.1002/14651858.CD006748.pub2

[8] McAlaney, J., Bewick, B. and Hughes, C. (2011) The international development of the "Social Norms" approach to drug education and prevention. Drugs: Education, Prevention and Policy, 18, 81-89. doi:10.3109/09687631003610977

[9] Perkins, J.M., Perkins, H.W. and Craig, D.W. (2010) Peer weight norm misperception as a risk factor for being over- and underweight among UK secondary school students. European Journal of Clinical Nutrition, 64, 965971. doi:10.1038/ejcn.2010.106

[10] Martens, M.P., Page, J.C., Mowry, E.S., Damann, K.M., Taylor, K.K. and Cimini, M.D. (2006) Differences between actual and perceived student norms: An examination of alcohol use, drug use, and sexual behavior. Journal of American College Health, 54, 295-300. doi:10.3200/JACH.54.5.295-300

[11] Moore, S.M. and Ohtsuka, K. (1999) The prediction of gambling behavior and problem gambling from attitudes and perceived norms. Social Behavior and Personality, 27, 455-466. doi:10.2224/sbp.1999.27.5.455

[12] Larimer, M.E. and Neighbors, C. (2003) Normative misperception and the impact of descriptive and injunctive norms on college student gambling. Psychology of Addictive Behaviors, 17, 235-243. doi:10.1037/0893-164X.17.3.235

[13] Neighbors, C., Lostutter, T.W., Whiteside, U., Fossos, N., Walker, D.D. and Larimer, M.E. (2007) Injunctive norms and problem gambling among college students. Journal of Gambling Studies, 23, 259-273. doi:10.1007/s10899-007-9059-3

[14] Grant. J.E., Potenza, M.N., Weinstein, A. and Gorelick, D.A. (2010) Introduction to behavioral addictions. American Journal of Drug Alcohol Abuse, 36, 233-241. doi:10.3109/00952990.2010.491884
[15] Holde, C. (2001) Behavioral addictions. Do they exist? Science, 294, 980-982. doi:10.1126/science.294.5544.980

[16] Shaffer, H.J. and Kidman, R. (2003) Shifting perspectives on gambling and addiction. Journal of Gambling Studies, 19, 1-6. doi:10.1023/A:1021267028254

[17] Neal, P., Delfabbro, P.H. and O’Neill, M. (2005) Problem gambling and harm: Towards a national definition. Final Report. Gambling Research Australia, Melbourne. http://www.adelaide.edu.au/saces/gambling/publications/ ProblemGamblingAndHarmTowardNationalDefinition.pdf

[18] Blinn-Pike, L., Worthy, S.L. and Jonkman, J.N. (2010) Adolescent gambling: A review of an emerging field of research. Journal of Adolescent Health, 47, 223-236. doi:10.1016/j.jadohealth.2010.05.003

[19] Järvinen-Tassopoulos, J. and Metso, J. (2009) Boys are players, girls are diletanttes-Reviewing the results of the 2007 ESPAD school survey, Yhteiskuntapolitiikka, 74, 523536.

[20] Rimpelä, A., Rainio, S., Pere, L., Lintonen, T. and Rimpelä, M. (2006) Use of tobacco products, alcohol use and exposure to drugs in 1977-2005. Reports of the Ministry of Social Affairs and Health. Helsinki, Finland. http://pre20090115.stm.fi/sl1152084751727/passthru.pdf

[21] Lewis, M.A. and Neighbors, C. (2004) Gender-specific misperceptions of college student drinking norms. Psychological Addictive Behavior, 18, 334-339. doi:10.1037/a0015176

[22] Jáuregui-Lobera, I., Bolaños-Ríos, P., Santiago-Fernández, M.J., Garrido-Casals, O. and Sánchez, E. (2011) Perception of weight and psychological variables in a sample of Spanish adolescents. Diabetes Metabolic Syndrome and Obesity, 4, 245-251.

[23] Neighbors, C., Lostutter, T.W., Larimer, M.E. and Takushi, R.Y. (2002) Measuring gambling outcomes among college students. Journal of Gambling Studies, 18, 339360. doi:10.1023/A:1021013132430 